This is the peer reviewed version of the following article: Zhang, W, Liu, M, Sadovy de Mitcheson, Y, et al. Fishing for feed in China: Facts, impacts and implications. Fish Fish. 2020; 21: 47-62, which has been published in final form at https://doi.org/10.1111/faf.12414. This article may be used for non-commercial purposes in accordance with Wiley Terms and Conditions for self-archiving.

\title{
Title: Fishing for feed in China: facts, impacts and implications
}

\section{Alternative title 1: Feed component of China's marine catch}

\section{Alternative title 2: Fishing for feed in China}

\section{Running title: Fishing for feed in China}

Wenbo Zhang ${ }^{1,10,11^{*}}$, Min Liu ${ }^{2 *}$, Yvonne Sadovy de Mitcheson ${ }^{3}$, Ling Cao ${ }^{4,5}$, Duncan

Leadbitter $^{6}$, Richard Newton ${ }^{7}$, David C. Little ${ }^{7}$, Songlin Li ${ }^{1,10,11}$, Yi Yang ${ }^{8}$, Xiao Chen $^{9} \&$ Wei

$Z$ Cu $^{8}$

${ }^{1}$ National Demonstration Center for Experimental Fisheries Science Education, Shanghai Ocean University, Shanghai 201306, China; ${ }^{2}$ State Key Laboratory of Marine

Environmental Science and College of Ocean \& Earth Sciences, Xiamen University, Xiamen 361 102, Fujian, China; ${ }^{3}$ School of Biological Sciences, Swire Institute of Marine Science, University of Hong Kong, Hong Kong 999077, China; ${ }^{4}$ Institute of Oceanography, Shanghai Jiao Tong University, Shanghai 200240, China; ${ }^{5}$ Center on Food Security and the Environment, Stanford University, Stanford CA 94305, USA; ${ }^{6}$ Australian National Centre for Ocean Resources and Security, University of Wollongong, Wollongong NSW 2522, Australia; ${ }^{7}$ Institute of Aquaculture, University of Stirling, Stirling FK9 4LA, United Kingdom; ${ }^{8}$ Greenpeace East Asia, Beijing 100007, China; ${ }^{9}$ College of Marine Science, South China Agricultural University, Guangzhou 510642, China; ${ }^{10}$ Shanghai Engineering Research Center of Aquaculture, Shanghai Ocean University, Shanghai 201306, China;

${ }^{11}$ Centre for Research on Environmental Ecology and Fish Nutrion of the Ministry of Agriculture, Shanghai Ocean University, Shanghai 201306, China

\section{Correspondence authors:}

Wenbo Zhang, National Demonstration Center for Experimental Fisheries Science Education, Shanghai Ocean University, Shanghai 201306, China. E-mail: wb-zhang@shou.edu.cn Min Liu, State Key Laboratory of Marine Environmental Science and College of Ocean \& Earth Sciences, Xiamen University, Xiamen 361102, Fujian, China. E-mail: minliuxm@xmu.edu.cn

Wei Zhou, Greenpeace East Asia, Beijing 100007, China. E-mail: zhou.wei@greenpeace.org *Wenbo Zhang and Min Liu contributed equally.

Competing interests: The authors declare no competing interests. 
Abstract: China is the world's largest capture fisheries and aquaculture producer. Over recent decades, China's domestic marine catch composition has changed markedly, from large volumes of a few high-valued food species to multiple, small, low-valued, species, a significant proportion of which is primarily used as animal, especially fish, feed. Despite the growing volume and economic importance of the feed catches, their species composition, catch volumes and socio-environmental impacts are all poorly understood. Based on a nationwide survey of $>800$ fishing vessels, and the identification and measurement of $>12,000$ fish and invertebrate individuals, the present study provides an overview of the feed component of China's domestic marine catch, by volumes, species, and sizes, and found it to be substantial and biologically unsustainable. Half of the trawler catch (3 million metric tons, $\mathrm{mmt}$ ), or $35 \%$ of the total catch $(4.6 \mathrm{mmt})$ in China's exclusive economic zone are now comprised of low-valued 'feed grade fish'. The present study identified 218 fish species, 50 crustaceans and five cephalopods and of these, 102 fish species were food species with $80 \%$ in their juvenile size ranges. Feed grade fish were mainly used as aquaculture feed directly, or indirectly through the feed industry after reduction to fishmeal and fish oil. The unparalleled scale and poor fisheries resource condition of China's domestic marine fisheries, in parallel with severe overfishing of juveniles, creates a demand for fundamental changes to fishery management practices, including a significant reduction of fishing effort to ensure productivity and ecosystem resilience.

Keywords: biodiversity, feed grade fish, management, multispecies fisheries, trash fish, trawl 


\section{Table of contents}

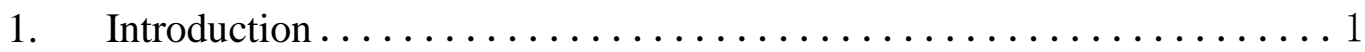

2. Methodology $\ldots \ldots \ldots \ldots \ldots \ldots \ldots \ldots \ldots \ldots \ldots \ldots \ldots \ldots \ldots \ldots \ldots \ldots$

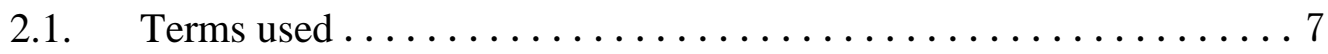

2.2. Fishing vessel/gear survey $\ldots \ldots \ldots \ldots \ldots \ldots \ldots \ldots \ldots$

2.3. Fish sampling, identification, and measurement $\ldots \ldots \ldots \ldots$.

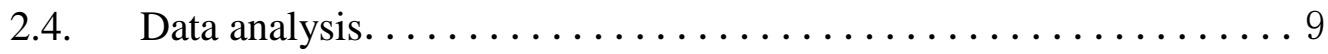

3. $\quad$ Results ............................... 11

3.1. Proportion of feed grade fish in catch $\ldots \ldots \ldots \ldots \ldots \ldots \ldots$

3.2. Feed grade fish production $\ldots \ldots \ldots \ldots \ldots \ldots \ldots \ldots \ldots \ldots \ldots$

3.3. Use and prices of feed grade fish $\ldots \ldots \ldots \ldots \ldots \ldots \ldots$

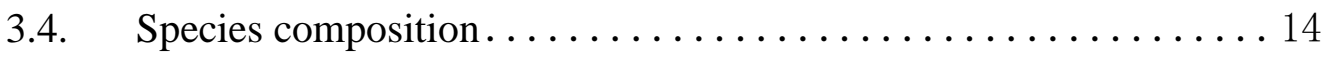

3.5. Food fish species and proportion of catches composed of juveniles . 15

3.6. Stock assessment and conservation status $\ldots \ldots \ldots \ldots \ldots$

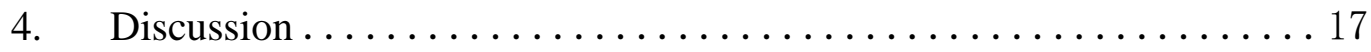

4.1. Fishing for feed in China is substantial and biologically unsustainable 17

4.2. Effective management is needed for both food and feed components 19

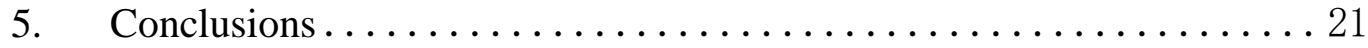

Acknowledgments................................ 23

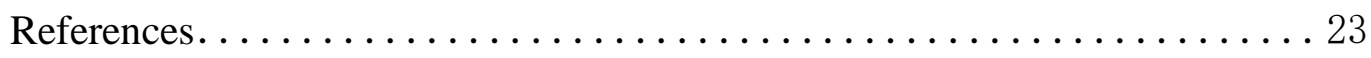




\section{Introduction}

China is the world's largest capture fisheries and aquaculture producing country, accounting for $19.2 \%$ of global marine capture fisheries production and $61.5 \%$ of global aquaculture production in 2016 (FAO 2018). In 2016, China's total domestic marine capture fisheries production was $13.3 \mathrm{mmt}$ (million metric tons), and total aquaculture (marine and freshwater) production was $51.4 \mathrm{mmt}$ (MOA 2017a). Capture fisheries and aquaculture in China provide food and income, 13.8 million jobs, and livelihoods for nearly 20 million people (MOA 2017a).

Despite the introduction of a range of marine fisheries management measures at both national and local levels since the 1980s (Cao et al. 2017), fishing pressure has grown over the last four decades (Figure S1). Persistently high fishing pressure, together with other pervasive deleterious anthropogenic influences, such as runoff of fertilizers and habitat loss and degradation, have resulted in sharp declines in fishery biomass and catch per unit effort (CPUE) in China's major fishing grounds. In the Bohai Sea, the CPUE declined from $>420 \mathrm{~kg} \mathrm{haul}^{-1} \mathrm{~h}^{-1}$ in 1959 , to ${ }^{\sim} 160 \mathrm{~kg} \mathrm{haul}^{-1} \mathrm{~h}^{-1}$ in 1982, $30 \mathrm{~kg} \mathrm{haul}^{-1} \mathrm{~h}^{-1}$ in 1993, and $<8 \mathrm{~kg} \mathrm{haul}^{-1} \mathrm{~h}^{-1}$ in 1998-2011 (Jin et al. 2013; Shan et al. 2013). In the Yellow Sea and East China Sea, the CPUE dropped from $73.54 \mathrm{~kg}$ haul $^{-1} \mathrm{~h}^{-1}$ to $39.19 \mathrm{~kg} \mathrm{haul}^{-1} \mathrm{~h}^{-1}$ in just ten years between 1991 to 2000 (Cheng and $\mathrm{Yu}$ 2004). In the northern South China Sea, the fishery biomass declined from $2.7 \mathrm{mt} \mathrm{km}^{-2}$ in the $1930 \mathrm{~s}$, to $1.5 \mathrm{mt} \mathrm{km}^{-2}$ in $1956,1.1 \mathrm{mt} \mathrm{km}^{-2}$ in $1960-1973$, and $0.3 \mathrm{mt} \mathrm{km}^{-2}$ in $1997-$ 1999 (Qiu 2002).

In concert with biomass and CPUE declines, the species composition of China's 
domestic marine catches over the past six decades has undergone substantial changes from a predominance of a few medium to relatively large-sized, high-valued, high trophic level, demersal species to multiple small, low-valued, short-lived, low trophic fishes (Liu and Sadovy de Mitcheson 2008; Shen and Heino 2014; Cao et al. 2017) (Figure S2). These changes are largely attributable to the overfishing of these larger species driven by ineffective management resulting in increased numbers of smaller, lower trophic level species (Pauly et al. 1998; Lundgren et al. 2006; Shen and Heino 2014; Cao et al. 2017).

Since the 1990s fisheries production has increasingly been used to supply fishmeal and animal feed, particularly aquaculture feed, shifting away from its historic use for direct human consumption. This pattern is observed not only in China (Funge-Smith et al. 2005; Lundgren et al. 2006; Cao et al. 2015), but also in Vietnam (Edwards et al. 2004) and several other Asian countries and areas (Funge-Smith et al. 2005). The increasing importance of animal feed during a period when food fisheries were declining enabled some fisheries to remain viable; for example in Hong Kong after declines in traditional trawl fisheries occurred due to overfishing, fishers were increasingly able to earn money from smaller, poorer quality fish, being sold as animal feed for the burgeoning mariculture sector. This enabled the fisheries to remain economically viable and allowing overfishing to continue (e.g. Hong Kong, Cheung and Sadovy 2004).

Due to the highly diverse nature of the world's fisheries and because of different terminologies and histories among countries (FAO 2011b), there is no single or 
consistent definition or term for fisheries fishing for feed, or their product, that clearly describes the specific proportion of the catch that to be used as aquaculture (or livestock) feed. In the past, when fisheries were in good condition and aquaculture less developed, small-sized, low-valued fish were typically discarded and variously referred to as 'discards' or 'bycatch' or 'trash fish', reflecting the fact that they were not targeted, were incidental, or were of little or no economic value, and often being unfit for human consumption due to small size and/or poor condition (Alverson et al. 1994; Nguyen et al. 2009; FAO 2011a). In the early days of fishery development, this discarding in Southeast Asia was responsible for an estimated loss of some $3.4 \mathrm{mmt}$ of fish catch per year (Chee 1997).

Other terms have been variously and inconsistently used, making comparisons across studies a challenge. Terms for the catch component not directly used for human food initially reflected what happened to the catch to, more recently, the fisheries that target fish used as feed. Catch terms range from 'pig fish' (Edwards et al. 2004; FungeSmith et al. 2005), 'low value/trash fish' (Funge-Smith et al. 2005; Lundgren et al. 2006), 'feed fish' (Huntington and Hasan 2009), to 'mixed fish feed' (Chau and Sadovy 2005). Although reduction fisheries have existed for centuries for industrial purposes (Smith 1991), as the use of catches for animal feed became more important, specific fisheries terminology began to be identified, such as feed fisheries (Hasan and Halwart 2009) and forage fisheries (Watson et al. 2006) which were used alongside the term 'reduction fisheries' (Parker and Tyedmers 2011; Shepherd and Jackson 2013). Some terms for this 'feed' component fisheries are no longer fit-for-purpose or are 
even misleading. The best example is the still widely used term 'trash fish'. As fisheries focused on food fish declined and aquaculture increased, a growing proportion of 'trash' fish was retained and came to have economic value in the aquaculture (or other livestock) sector (Alverson et al. 1994; Funge-Smith et al. 2005; Zeller et al. 2018). Moreover, what may be bycatch in one fishery or in one season, may be valuable food fish in another or would become food fish if animals were retained in better condition or were taken at larger body sizes.

Along with the development of aquatic food processing technologies and improvements in the handling of fish, there was also a rapid expansion of markets for other human food products such as surimi, fish balls, sauces or pastes. Species used to be by-catch but suited for processing into surimi are increasingly targeted or diverted from the fishmeal supply chain and used as raw material (Siriraksophon et al. 2009; Funge-Smith et al. 2012; Anon 2016).

While in many parts of the world the 'feed' component is primarily (if not solely) caught from targeted forage (or reduction) fisheries (Hasan and Halwart 2009; FAO 2011a), the sourcing of it in China is more complicated. This is because multiple fishing gears are involved which take a complex mix of species that are both targeted and nontargeted and can be used as direct feed for aquatic animals and, indirectly, to produce fishmeal, or for direct human consumption, according to their condition, species and size. In the present study, we use the term 'feed grade fish' to describe those fish (and invertebrates) that are targeted or retained to be used as fish or livestock feed. Over the past two decades, fishing for feed grade fish in China has become 
increasingly important, due to overfishing of food fish associated with poor fisheries management, and, growth in demand for feed grade fish, especially with the development of aquaculture (Naylor et al. 2000; Funge-Smith et al. 2005; Huntington and Hasan 2009; Cao et al. 2015). Into the new millennium, China's aquaculture has been greatly intensified with much more formulated feed and direct feeding of feed grade fish required (Edwards 2008a,b; Chiu et al. 2013), with a trend to 'farming up' the food web with increasingly more high value species, especially carnivore species, being farmed (Naylor et al. 2000; Miao and Liao 2007; Zhou 2007), further contributing to the increasing demand for feed grade fish.

The feed component is today a significant aspect of China's domestic marine fisheries. Estimates based on FAO data over a decade ago show that the feed component represented more than one-third of China's marine catch (Han and Xu 2004; FungeSmith et al. 2005; FAO 2007) and was mainly constituted by unidentified 'nei' (not elsewhere included) species and forage species (Han and Xu 2004; Cao et al. 2015). Sporadic surveys also suggest that $26-90 \%$ of the fisheries catch by weight or number in China's EEZ are feed grade fish, especially from non-targeted trawls and stow nets, in some cases higher than the situation found in other Southeast Asian countries (Table S1) but similar to countries where targeted reduction fisheries are operating.

However, the feed component of China's domestic marine fisheries has not been documented systemically at the national level. Its scale, species composition, as well as biological, ecosystem and management implications are poorly understood. For example, 'nei' accounts for approximately $31 \%$ of China's domestic marine catch (Cao 
et al. 2015), but its composition is largely unknown. This situation makes it difficult to assess the impact of the source fisheries and seriously constrains the development of effective management.

Meanwhile, there are growing concerns that the demonstrable declines in largescale, and unmanaged, fisheries bring substantial risks to the marine ecosystem, threaten biodiversity and endanger long-term marine ecosystem resilience. One critical risk is that further overfishing of a wide range of species and sizes in China EEZ will seriously reduce the future productivity of marine fisheries (Cao et al. 2015, 2017).

The objectives of the present study were to reveal the complicated nature of the feed component of China's domestic marine catch, related fisheries, volumes, species composition, destination/use of catches, and its impacts and implications without management. A better understanding of the current situation of China's domestic marine fisheries, especially the little-understood component used as feed can provide a solid basis for supporting future policy reforms in China's marine fisheries sector.

\section{Methodology}

The present study adopted an integrated, interdisciplinary methodology by combining both top-down and bottom-up approaches to develop a holistic understanding of the feed component of China's domestic marine catch. We started from systematic literature reviews then proceeded to a nationwide field survey of fishing vessels/gears and analysis of feed grade fish samples, collected in eight major fishing provinces (Tables S2 and S3; Figure S3).

Field survey and feed grade fish sampling were focused on the most important 
fishing months from August to December in 2016, which is right after the national fishing moratorium and prior to the winter when fishing activities were largely closed in the north. In 2016, the total capture fisheries production (both marine and freshwater) in the second half of the year was $11.69 \mathrm{mmt}$, which accounts for $66.4 \%$ of annual production (Economic Daily 2016; MOA 2017a).

\subsection{Terms used}

In the present study, domestic marine fisheries catches were classified into three categories: (1) food species; (2) forage species, particularly small pelagic and planktivorous species; and (3) all other mixed species, mainly used for aquaculture feed (Table 1). In relation to supplying the animal feed sector, we suggest that the term 'feed grade fish' for catch used as animal feed (either directly, or indirectly after reduction), which consists of a wide range of species and sizes from small-sized individuals of food species (category 1), forage species (category 2) to mixed species (category 3). Specifically, 'feed grade fish' refers to the mixture of poorly preserved, small-sized and low commercial-value fishes and invertebrates primarily used as animal feed. The term 'feed grade fish' refers to 'Xiao Za Yu' in Mandarin, which literal translation is 'small and miscellaneous fish'.

\subsection{Fishing vessel/gear survey}

Fishing vessel/gear surveys were conducted in December 2016. The sampling of fishing vessels for interviews followed a multi-stage sampling approach from provincial level to district and port levels. Eight major marine fisheries provinces were selected for the survey: Liaoning, Shandong, Jiangsu, Zhejiang, Fujian, Guangdong, 
Guangxi, and Hainan. The total marine catch in these eight provinces represented 97.7\% of the national domestic marine catch in 2016 (Table S2). The most important one or two districts for marine capture fisheries in each province, in terms of the number of fishing vessels and landing volumes, giving a total of 22 fishing ports in 12 districts, were selected for the surveys (Table S3; Figure S3).

Surveys covered the following areas of interest. (1) Basic information about interviewees such as position, name, age, and contact information. (2) Vessel information such as registration number, length, and horsepower. (3) Major fishing areas and major fishing gears. (4) Total catch of food species in different taxonomic groups (i.e. fishes, cephalopods, crustaceans and others). (5) Total catch of feed grade fish (i.e. the fish is marketed as such). (6) Catches of major species among food species. (7) Major species of feed grade fish. (8) Destination and price of feed grade fish. Survey questions were designed to cover the whole fishing season in the second half of 2016 (August to December).

Fishing vessel surveys at port level were primarily conducted according to fishing gear type. Fishing gears were classified according to The International Standard Statistical Classification of Fishing Gear (FAO 2016) and standards in publications (Wang and Yu 2012; Hainan Aquaculture Institute 2013; Sun 2014). Survey sample sizes for each fishing gear category were at least 30 , except for trawler. The trawler was the focus of the present study because trawlers produce half of China's marine catch by weight in the EEZ (Figure S4) and account for a high proportion of feed grade fishes (Table S1). Survey sample sizes for trawler in each selected province were at least 30. 
The term 'trawler' covers vessels that may target feed grade fish (especially midwater trawlers) and those that catch feed grade fish incidentally (generally bottom trawlers). Fishing vessels were randomly selected in each port, with interviewees being mainly fishing vessel owners, captains, or senior fishers.

\subsection{Fish sampling, identification, and measurement}

From August to December 2016, feed grade fish samples of up to $1 \mathrm{~kg}$ in weight were collected 2-3 times per month in each of eight provinces directly from fishing vessels. Species were identified, and individuals were counted and measured for body weight and length. Identified species from collected samples were classified as food species, forage species, or mixed species based on the opinions of four experts from different research institutes. Classifications also referenced major aquatic trading websites, and marine capture species lists in the FAO FishstatJ database (FAO 2017), China Fishery Statistical Yearbook (MOA 2017a), the list of commercially important aquatic animals and plants under special national protection for resources (MOA 2017b), the standard of catchable size of important fisheries species part 1 (economic marine species (MOA 2017c)), and marine capture species information in FishBase (Froese and Pauly 2017). The IUCN Red List Status of Threatened Species (www.iucnredlist.org) was referred to for conservation status of identified species. Stock assessments from fisheries in China or the wider SE Asia region were collected from FAO evaluations and related publications.

\subsection{Data analysis}

A multiple linear regression model was used to investigate factors contributing to 
different proportions of feed grade fish in catches using SPSS 22 statistics software (IBM 2013). All fishing vessels surveyed were classified into one of three length categories $(<12 \mathrm{~m}, 12-24 \mathrm{~m},>=24 \mathrm{~m})$ according to the China Fisheries Yearbook (MOA 2017a). The proportion of feed grade fish in catches was calculated based on survey results for all major fishing gears surveyed across all eight provinces. Using marine fisheries production by province and fishing gear type as a weighting factor for proportion of feed grade fish, the overall proportion of feed grade fish for the whole country was calculated. Independent-samples Kruskal-Wallis test was used for significance test using SPSS 22 statistic software (IBM 2013). The Chinese Yuan (CNY) was converted to US dollars (USD) using the annual average exchange rate in 2016 as $1 \mathrm{USD}=6.66 \mathrm{CNY}$ (https://www.investing.com/).

Maturity stage was inferred from knowledge of recorded or estimated size (body length) at first maturity (Lm). Lm was collected from FishBase (Froese and Pauly 2017). When the recorded Lm for a species was missing, the estimated Lm in the FishBase Species Ecology Matrix was used; estimated Lm was calculated from the recorded asymptotic length of a species and an empirical relationship between length at first maturity and asymptotic length (Froese and Binohlan 2000; Froese and Pauly 2017).

Several potential sources of variation and uncertainty in the present study (Appendix S1) could affect the calculations of total feed grade fish volume as well as feed grade fish sampling. To estimate the aggregate impact of data uncertainty on feed grade fish production in China, a Monte Carlo analysis was conducted in Oracle Crystal Ball (Release 11.1.2.3.500). The Monte Carlo method is extensively used in fisheries 
research to estimate uncertainty by repeated random sampling based on predefined parameters of probability distributions (Pauly et al. 2014). The type of probability distributions and uncertainty parameters for the model were calculated by the Batch Fit module in Oracle Crystal Ball and based on survey data of the present study. The uncertainty parameters represented variations in the proportion of feed grade fish from different fishing gear category. We calculated uncertainty based on a distribution of 100,000 runs resulting from the Monte Carlo sampling method.

A sensitivity analysis was conducted to explore the juvenile percentages associated with variation of length at sexual maturity (Appendix S1). Instead of using the estimated Lms, body length at $50 \%$ of the maximum body length (L50) reported in the FishBase (Froese and Pauly 2017) was used as a comparable criterion for the size of sexual maturation.

\section{Results}

\subsection{Proportion of feed grade fish in catch}

A total of 886 interviews was conducted from domestic vessels in 22 major fishing ports in eight major fishing provinces in December 2016 (Tables S3 and S4). The multiple linear regression model shows fishing gear and sampling location (province) to be the major factors associated with different proportions of feed grade fish (including fishes and invertebrates) in catches ( $\mathrm{p}<0.05$; Table S5). The average engine power of fishing vessels, according to respondents willing and able to answer this question, was $410.5 \pm 343.3 \mathrm{~kW}(\mathrm{n}=582)$ and the average vessel length is $31.3 \pm 10.0 \mathrm{~m}$ $(\mathrm{n}=851)$ (Figure S5). Although large fishing vessels produced significantly more catch 
per vessel than small fishing vessels (Table S6), vessel size (length) has little effect on the proportion of feed grade fish in catches (Table S7).

Trawls, stow nets, gillnets and entangling nets, and surrounding nets and seine nets were identified as the main fishing gears taking feed grade fish. Trawls accounted for the highest proportion of feed grade fish catch overall by weight (Figure 1), with nearly as midwater trawls primarily target forage fishes, mainly anchovies in the Bohai and Yellow Seas, producing $71.5 \pm 31.2 \%(\mathrm{n}=76)$ of feed grade fish as a proportion of their total catch by weight. This was significantly $(\mathrm{p}<0.05)$ higher than the proportion taken animal feeds. half $(48.9 \pm 26.5 \%, \mathrm{n}=538)$ of trawler catches being feed grade fish. This is not surprising from bottom trawlers $(43.6 \pm 21.3 \%, \mathrm{n}=336)$ (Table 2$)$ and probably reflects the fact that midwater trawls are used to target small pelagic species that are commonly used for

Three-fifths $(58.5 \%)$ of trawlers, $46.6 \%$ of stow net vessels, $23.5 \%$ of gillnet and entangling net vessels, and $7.1 \%$ surrounding nets and seine nets vessels by number, were predominantly producing feed grade fish, which accounting for at least $50 \%$ of their total catch by weight (Figure 2). Trawlers in Liaoning, Shandong, Guangxi, and Hainan reported significantly higher proportions of feed grade fish in their catches than other provinces $(\mathrm{p}<0.05)$ (Table 3$)$.

\subsection{Feed grade fish production}

The overall proportions of feed grade fish, according to 886 interviews, weighted by production by gear and province (Tables 4 and 5) show that $34.7 \%$ of China's marine catch, or $4.6 \mathrm{mmt}$ marine fisheries production, was feed grade fish. The Monte Carlo 
analysis also shows that about $4.6 \mathrm{mmt}$ ( $95 \%$ confidence interval: $2.1-7.0 \mathrm{mmt}$ ) of total production was feed grade fish (Figure S6, Table S8).

The proportion of feed grade fish produced by all trawlers combined, weighted by production by province, was $48.7 \%$, which is equivalent to $3.0 \mathrm{mmt}$ of feed grade fish production from China's EEZ (Table 5). This is followed by stow nets $0.7 \mathrm{mmt}$, gillnets and entangling nets $0.6 \mathrm{mmt}$ and surrounding nets and seine nets $0.2 \mathrm{mmt}$ (Table 5). Shandong, Guangxi, and Zhejiang had the highest proportions of feed grade fish (Figure 3) in their catches, reflecting the reliance of these provinces on trawlers (Figure S7). The top capture fisheries provinces are also major feed grade fish producing provinces, especially Zhejiang and Shandong (Figure 4; Table S2).

\subsection{Use and prices of feed grade fish}

A total $88.2 \%$ of interviewees $(n=781)$ reported that their feed grade fish catch was mainly used in the aquaculture and feed industries, either as direct feed (e.g. using unprocessed whole fish or fish parts directly in aquaculture cages/ponds) or indirectly to produce fishmeal and fish oil which is then used as raw material for aquaculture and livestock feed (Figure 5). Some mink and fox farms in Shandong and Liaoning, and, occasionally, chicken and pig farms in fish-producing areas, also use feed grade fish but the scale of this use is not known. A low proportion (4.9\%) of the interviewees $(n=43)$ reported discarding feed grade fish because of poor condition, while $6.7 \%(n=59)$ reported their catch was mainly used for human consumption after processing into minced products such as fish balls, dried or salted product, or sauces and pastes. The consumption of feed grade fish $(4.6 \mathrm{mmt})$ was estimated according to survey data 
(Figure 6).

Prices of feed grade fish purchased from fishing vessels or at fishing ports varied from USD 0.1 to 0.8 per $\mathrm{kg}$ and averaged USD $0.2 \pm 0.1$ per $\mathrm{kg}(\mathrm{n}=684)$ depending on province, freshness/quality, species composition, the type of utilization intended, and the demand for feed grade fish by the aquaculture sector (Figure S8). Small size and poor condition of feed grade fish led to particularly low prices, making them affordable for purchase and use whole by aquaculture producers or for manufacturing of fishmeal. A nationwide feed grade fish value chain has developed, and a stable market and price structure for feed grade fish now exists. Feed grade fish transactions take place both within the capture fisheries sector and across a trade chain that links feed grade fish capture to transportation networks by sea or by land and involving cold storage, with aquaculture farms and fishmeal factories as major end-users. The trade network runs across the country; for example, feed grade fish caught in Zhejiang could supply aquaculture farms in Fujian, and fishmeal factories in Shandong.

\subsection{Species composition}

A total of 80 samples of feed grade fish, with a total weight of $64.4 \mathrm{~kg}$, after removing unidentifiable fish and invertebrate body parts and garbage, were collected from 22 fishing ports surveyed throughout eight major marine fisheries provinces. A total of 12,206 individuals were measured, the majority being fish, with $10,796(88.5 \%)$ individuals, followed by 1,263 (10.4\%) crustaceans, and 147 (1.2\%) cephalopods. 
including three Chondrichthyans (two orders and two families) and 215

310 Actinopterygiians (19 orders and 84 families) (Figure 7; Figure S9, Tables S9-S11).

The most numerous fish families were Engraulidae (3,668 individuals from 10 species),

Gobiidae (1,852 individuals from 14 species), Clupeidae (752 individuals from 8 species), Synodontidae (734 individuals from 5 species), Bregmacerotidae (632

314 individuals from 1 species), and Sciaenidae (488 individuals from 17 species). In 
Binohlan 2000; Tsikliras and Stergiou 2014; Froese and Pauly 2017). Most of the fish species identified in this study are small-sized species (Tables S9-S11), and their estimated Lm's are more likely longer than the sizes of 50\% of the maximum body length.

\subsection{Stock assessment and conservation status}

Of 218 fish species identified, stock assessments published in reports, books or papers from 2005 to 2015 were found for 32 species and taxonomic groups (to genus level), of which $28(87.5 \%)$ were over-exploited, and 4 (12.5\%) were fully exploited or starting to decline at the time of reporting, all were Actinopterygiians (Tables S14 and S15).

In terms of conservation status, 143 fish species have not been evaluated (NE) against the IUCN Red List Criteria. Among the 72 species evaluated, one was endangered (EN, Evynnis cardinalis), one vulnerable (VU, Nemipterus virgatus), 59 least concern (LC), and 11 data deficient (DD) (Tables S9-S11).

Eight species of fish, one crustacean, and one cephalopod have been important for China's national stock enhancement projects (Table S16). Of these ten species, most individuals taken in samples of the current study were still in their juvenile stage. National stock enhancement projects, therefore, are likely being compromised by uncontrolled fisheries that catch feed grade fish as these projects rely on the dispersal of juvenile fish into the wild. 


\section{Discussion}

\subsection{Fishing for feed in China is substantial and biologically unsustainable}

Although the reported production from China's fishing grounds remained stable over multiple years, an increasing and significant proportion of domestic marine catch comprises poorer quality fish, less marketable as direct human food than previously, and now primarily used as animal feed. The loss of historically major food fisheries, declining fisheries biomass and CPUE, changing species composition, declining fish size, and shifting end use of marine catch, primarily driven by severe overfishing and excessive capture of juveniles, are trends that have largely been obscured by this stable reported production.

At the global level, around one-quarter, or $20 \mathrm{mmt}$, of fisheries landings were used for purposes other than direct human consumption (FAO 2018). The present study found that about $35 \%(4.6 \mathrm{mmt})$ of China's marine catch is now sold at low prices as feed grade fish, $40 \%$ higher than the global average. Considering China's feed grade fish production alone would rank it fourth among World's leading marine fisheries countries (Figure 9).

Thirty percent (29.4\%) of feed grade fish catch was identified as food fish species, with most of these $(79.7 \%)$ in their juvenile size range. If allowed to reach marketable size, these fish could potentially have gone directly to human food use and gained higher prices, which in turn would maximize yield or, at least, optimize individual value per recruit (Beverton and Holt 1993; Froese et al. 2016; Cashion et al. 2017) (also see Table S17). Forage fish are also overfished in China, with $71.8 \%$ of the individuals 
sampled being juveniles. This is in contrast to many of the World's major reduction fisheries that specifically target forage fish which are effectively managed using a variety of catch control tools, such as quotas and effort limits (Tveteras et al. 2011; Pikitch et al. 2012).

Protecting juveniles is a core component of fisheries management and sustainable resource use (Garcia et al. 2003; Crowder et al. 2008; Pinsky et al. 2011; Froese et al. 2016). There are examples of fisheries collapses of multiple different individual species stocks associated with depletion of adult individuals and an increasingly high proportion of juveniles in catches. For example, the large yellow croaker was heavily exploited to the point of severe depletion in the 1980s with an increasingly heavy take of juveniles (Liu and Sadovy de Mitcheson 2008) (Figure S11). Trends of increasingly higher proportions of juveniles in catches were also observed with many other major food species such as Largehead hairtail (Trichiurus lepturus), Yellow croaker (Larimichthys polyactis), Silver pomfret (Pampus argenteus) and Japanese Spanish mackerel (Scomberomorus niphonius) (Figure S12).

The outcomes of decades of overfishing and excess fishing capacity in China's domestic marine fisheries resulted in depletions of some 'traditionally taken' species by the 1970 s and 1980s. By the 1980s and 1990s, some forage species and recently exploited food species such as the scaly hairfin anchovy (Setipinna taty) and the filefish (Thamnaconus modestus) had also become over-exploited (Figure S2). The mean trophic level of China's marine catch has declined from 3.7 to 3.46 during the past halfcentury (Cao et al. 2017), which is linked to the expanding proportion of low-trophic- 
level forage species in catches, eroding biodiversity and degrading marine ecosystem structure, functioning and resilience (Smith et al. 2011). Unmanaged over the long term, there is a real risk that the fishery resources underpinning the feed component of China's marine catch will also inevitably collapse (Beverton 1990; Costello 2017) (Figure S2).

\subsection{Effective management is needed for both food and feed components}

China has regulations, policies and measures aimed at controlling fishing capacity, including a fishing license system, fishing moratorium, and minimum mesh size regulation (Cao et al. 2017). However, these efforts have clearly been inadequate in part due to ineffective compliance/enforcement of regulations but also because these measures do not control fishing effort. For example, along with depleted traditional fisheries resources, fishers tend to reduce their mesh size to maintain or increase their catches (Yu 2003); the legal minimum stretched mesh size requirement of $25 \mathrm{~mm}$ (which is still lower than $40 \mathrm{~mm}$ recommended by the APFIC Trawl Guidelines (FAO 2014a)) is poorly implemented. Cod-end mesh sizes net of $10 \mathrm{~mm}$ or less are extensively used by Chinese trawlers (Liang and Pauly 2017).

China's fisheries resources have been over-exploited since the 1970s, well before the development of intensive feed and aquaculture industries. Indeed, the aquaculture industry could be considered a beneficiary of changed marine catch composition. Although aquaculture development and intensification was not the direct cause of overexploited fisheries resources in China, the rapid development of the feed and aquaculture industries in China fueled a high market demand for feed grade fish and 
provided new incentives to continue fishing even as traditional fisheries were being depleted. In this way, the high demand for feed exacerbated the already overfished state of resources allowing fishers to continue making money even as the ecosystem became further degraded.

With globally expanding aquaculture, fishmeal prices in the international market have more than tripled over the past decade (FAO 2014b) (also see Figure S13), and the price of domestically produced fishmeal has increased in tandem. The high demand for fish feed from the aquaculture sector is supported by a large number of fishmeal factories. Their operation, often well below full capacity (20-45\% in 2016 (Wang 2017)), suggests increasing competition for scarce supplies. Such pressures place further stress on overexploited fishery resources.

The fishery fuel subsidy policy was introduced in 2006 in China and became the most important type of fishery subsidy in the country, accounting for $94 \%$ of overall fishery subsidies (Mallory 2016). The fuel subsidy covers about one-third of the total cost of marine capture fisheries (Zhu and Huang 2014). Without fuel subsidies, more than $90 \%$ of fishing vessels would lose money (Guo 2015). Economic incentives, from increasing demand for feed grade fish, high fuel subsidies, along with depletion of traditional fishing target species, further increase the motivation for overfishing.

The unparalleled scale (i.e. high volume) and poor fisheries resources condition (i.e. highly depleted) of China's domestic marine fisheries make them distinctive and the solutions to the problems created need to be large-scale and must significantly reduce current levels of fishing effort. China, like many other tropical and sub-tropical 
Asian countries (Leadbitter 2013), has a high biodiversity of fishes. The best option for managing the take of hundreds of different species, on the one hand, while addressing conservation principles that reduce threats to species and maintain functional marine ecosystems, may not be to seek Maximum Sustainable Yield (see for example Sainsbury 1984 (Sainsbury 1984)). One alternative is to generate a 'Pretty Good Yield' (Rindorf et al. 2017a,b) conditions with acceptable trade-offs where marine ecosystems are able to satisfy diverse societal needs ensuring most stocks and the ecosystem are protected or remain biologically viable (Cheung and Sumaila 2008; FAO 2014a; Costello 2017). Conservation measures, such as marine protected areas, can be used to safeguard key spawning and nursery areas that enable species to replenish themselves (Edgar et al. 2014; Hastings et al. 2017; Roberts et al. 2017).

By reducing excess fishing capacity, safeguarding key life history times and/or places, and effectively enforcing the current minimal mesh size requirement, fishery collapse could be averted, fisheries biomass, total catch and value could be increased, and the catch profile could be shifted to favor a greater proportion of larger fish (Jacobsen et al. 2013; Costello 2017; Szuwalski et al. 2017). This could also produce a better mix of products for direct human consumption, and indirectly via fish and livestock feed.

\section{Conclusions}

Significant changes in species composition in catches, the high proportion of catch comprised of juveniles, and loss of or severe declines in traditionally important fisheries are clear evidences of weak fisheries management and decades-long history of 
persistent overfishing and excess fishing capacity in China's domestic marine fisheries.

The growing proportion of catch used to supply the aquaculture sector since the 1990s has meant that pressure continues to be high across the coastal ecosystem, even as these declines and shifts occur. To date, commitments to resolve fishery issues remain unfulfilled and existing management measures have been ineffective.

Under current fishery policy, China's fisheries risk a further downwards shift due to intensification of both fishing down and farming up the food web (Pauly et al. 1998; Naylor et al. 2000; Tacon et al. 2010). Unchecked, this trajectory will continue and could ultimately result in an ecosystem shift towards species that have little or no human value and other challenges of ecosystem degradation, some of which may not be reversible, and which may not even be able to supply feed grade fish into the future. There is also a long-term threat associated with loss of marine biodiversity and loss of ecosystem function and resilience.

Based on the outcomes of the present study, it is clear that the feed component of China's marine catch should be documented and managed as part of the overall national planning for sustainable fisheries resources use and marine ecosystem management. A biologically sustainable balance between fishing for food and fishing for feed could be achieved to produce a better mix of products by effectively managing China's multispecies fisheries and reducing excessive fishing capacity, while not further compromising the ecosystem and associated biodiversity. Overall, a more ecosystemlevel and precautionary approach is needed for fisheries management, aquaculture development (such as a better selection of species cultured), including management of 
the feed component of China's marine catch to ensure long-term sustainability.

\section{Acknowledgments}

This study was motivated by the two symposiums on 'Fisheries and Food Security in China' hosted by Stanford University's Center on Food Security and the Environment (FSE). Wenbo Zhang is supported by the China-ASEAN Maritime Cooperation Fund. Min Liu is supported by the National Natural Science Foundation of China (No. 41476149), and the State Oceanic Administration of China (220203993022761133). Yvonne Sadovy de Mitcheson received funds from ADM Capital Foundation and Swire Trust. Thanks to Zhuocheng Zhou, Ruiqiang Zheng and Xiaoyun Tang for field survey and specimen collection, to more than 20 volunteers and employees in local fisheries cooperatives, and to Weidi Yang and postgraduates at Fish Biology Laboratory of Xiamen University for species identification and measurement assistant. Comments and suggestions for the original research report from anonymous experts at the Chinese Academy of Fishery Sciences, Shanghai Ocean University, and Xiamen University are much appreciated. Figure 6 produced using Sankey Flow Show software (https://www.sankeyflowshow.com/index.html).

\section{References}

Alverson, D.L., Freeberg, M.H., Murawski, S.A. and Pope, J.G. (1994) A global assessment of fisheries bycatch and discards (FAO Fisheries Technical Paper No. 339). Rome.

Anon (2016) Fisheries Statistics of Thailand 2014. No. 11 / 2016, Information and Communication Technology Center, Department of Fisheries, Ministry of Agriculture and Cooperatives.

Beverton, R.J.H. (1990) Small marine pelagic fish and the threat of fishing; are they endangered? Journal of Fish Biology 37, 5-16.

Beverton, R.J.H. and Holt, S.J. (1993) On the Dynamics of Exploited Fish Populations. Springer Netherlands, Dordrecht.

Cao, L., Chen, Y., Dong, S., et al. (2017) Opportunity for marine fisheries reform in China. Proceedings of the National Academy of Sciences 114, 435-442.

Cao, L., Naylor, R., Henriksson, P., Leadbitter, D., Metian, M., Troell, M. and Zhang, W. (2015) China's aquaculture and the world's wild fisheries. Science 347, 133-135.

Cashion, T., Le Manach, F., Zeller, D. and Pauly, D. (2017) Most fish destined for fishmeal production are food-grade fish. Fish and Fisheries 18, 837-844.

Chau, G.T.H. and Sadovy, Y. (2005) The use of mixed fish feed in Hong Kong's mariculture industry. World Aquaculture 36, 6.

Chee, P.E. (1997) A review of the bycatch and discards in the fisheries of Southeast Asia. In: Papers 
presented at the Technical Consultation on Reduction of Wastage in Fisheries. Tokyo. FAO Fisheries Report No. 547 (Suppl.). (eds I.J. Clucas and D.G. James). Rome, FAO, Tokyo, pp 257-274.

Cheng, J. and Yu, L. (2004) The change of structure and diversity of demersal fish communities in the Yellow Sea and East China Sea in winter (in Chinese). Journal of Fisheries of China 28, 29-34.

Cheung, W.W.L. and Sadovy, Y. (2004) Retrospective evaluation of data-limited fisheries: A case from Hong Kong. Reviews in Fish Biology and Fisheries 14, 181-206.

Cheung, W.W.L. and Sumaila, U.R. (2008) Trade-offs between conservation and socio-economic objectives in managing a tropical marine ecosystem. Ecological Economics 66, 193-210.

Chiu, A., Li, L., Guo, S., Bai, J., Fedor, C., Naylor, L.R. and Naylor, R.L. (2013) Feed and fishmeal use in the production of carp and tilapia in China. Aquaculture 414-415, 127-134.

Costello, C. (2017) Fish harder; catch more? Proceedings of the National Academy of Sciences 114, 1442-1444.

Crowder, L.B., Hazen, E.L., Avissar, N., Bjorkland, R., Latanich, C. and Ogburn, M.B. (2008) The Impacts of Fisheries on Marine Ecosystems and the Transition to Ecosystem-Based Management. Annual Review of Ecology, Evolution, and Systematics 39, 259-278.

Economic Daily (2016) The main indicators of fishery in China have improved in the first half of 2016 (in Chinese). Rural Know-All, 13.

Edgar, G.J., Stuart-Smith, R.D., Willis, T.J., et al. (2014) Global conservation outcomes depend on marine protected areas with five key features. Nature 506, 216-220.

Edwards, P. (2008a) Rural aquaculture: from integrated carp polyculture to intensive monoculture in the Pearl River Delta, South China. Aquaculture Asia Magazine, 3-7.

Edwards, P. (2008b) The Changing Face of Pond Aquaculture in China. Global Aquaculture Advocate, 77-80.

Edwards, P., Tuan, L.A. and Allan, G.L. (2004) A survey of marine trash fish and fish meal as aquaculture feed ingredients in Vietnam. ACIAR Working Paper No. 57. Australian Centre for International Agricultural Research.

FAO (2014a) APFIC/FAO Regional Expert Workshop on "Regional guidelines for the management of tropical trawl fisheries in Asia”. Phuket, Thailand, 30 September-4 October 2013. Bangkok, Thailand.

FAO (2011a) Aquaculture development. 5. Use of wild fish as feed in aquaculture.

FAO (2017) FishstatJ.

FAO (2011b) International Guidelines on bycatch management and reduction of discards.

FAO (2016) Revised International Standard Classification of Fishing Gears (ISSCFG, Rev.1 21 October 2010). 2.

FAO (2007) The state of world fisheries and aquaculture 2006. Food and Agriculture Organization of the United Nations, Rome.

FAO (2014b) The state of world fisheries and aquaculture 2014. Food and Agriculture Organization of the United Nations, Rome.

FAO (2018) The state of world fisheries and aquaculture 2018 - Meeting the sustainable development goals. Food a Agricultural Organization of the United Nations, Rome.

Froese, R. and Binohlan, C. (2000) Empirical relationships to estimate asymptotic length, length at first maturity and length at maximum yield per recruit in fishes, with a simple method to evaluate length frequency data. Journal of Fish Biology 56, 758-773. 
Froese, R. and Pauly, D. (2017) FishBase. Available at: www.fishbase.org [Accessed August 1, 2017]. Froese, R., Winker, H., Gascuel, D., Sumaila, U.R. and Pauly, D. (2016) Minimizing the impact of fishing. Fish and Fisheries 17, 785-802.

Funge-Smith, S., Briggs, M. and Miao, W. (2012) Regional overview of fisheries and aquaculture in Asia and the Pacific 2012.

Funge-Smith, S., Lindebo, E. and Staples, D. (2005) Asian fisheries today: The production and use of low value/trash fish from marine fisheries in the Asia-Pacific region. Rap Publication 2005/16, 47.

Garcia, S.M., Zerbi, A., Aliaume, C., Do Chi, T. and Lasserre, G. (2003) The ecosystem approach to fisheries. Issues, terminology, principles, institutional foundations, implementation and outlook. FAO Fisheries Technical Paper. No. 443. FAO, Rome.

Guo, X. (2015) Research on Diesel Subsidy Policy Influence on Ningbo Ocean Fishing (in Chinese). Hainan Aquaculture Institute (2013) Marine fishing gears and fishing methods in South China Sea. China Ocean Press, Beijing.

Han, J. and Xu, H. (2004) Overview of Status and Trend of Trash Fish from Marine Fisheries and Their Utilization, With Special Reference to Aquaculture THE BASIC STATUS OF TRASH FISH IN CHINA. Qingdao.

Hasan, M. and Halwart, M. (2009) Fish as feed inputs for aquaculture: Practices, sustainability and implications. Practices, sustainability and implications, 407.

Hastings, A., Gaines, S.D. and Costello, C. (2017) Marine reserves solve an important bycatch problem in fisheries. Proceedings of the National Academy of Sciences 114, 201705169.

Huntington, T. and Hasan, M. (2009) Fish as feed inputs for aquaculture - practices, sustainability and implications: a global synthesis. In: Fish as feed inputs for aquaculture: Practices, sustainability and implications. (eds M.R. Hasan and M. Halwart). FAO Fisheries and Aquaculture Technical Paper. No. 518., Rome, pp 1-61.

Jacobsen, N.S., Gislason, H. and Andersen, K.H. (2013) The consequences of balanced harvesting of fish communities. Proceedings of the Royal Society B: Biological Sciences 281.

Jin, X.S., Shan, X.J., Li, X. Sen, Wang, J., Cui, Y. and Zuo, T. (2013) Long-term changes in the fishery ecosystem structure of Laizhou Bay, China. Science China Earth Sciences 56, 366-374.

Leadbitter, D. (2013) A risk based approach for promoting management regimes for trawl fisheries in South East Asia. Asia Fisheries Science 26, 65-78.

Liang, C. and Pauly, D. (2017) Growth and mortality of exploited fishes in China's coastal seas and their uses for yield-per-recruit analyses. Journal of Applied Ichthyology 33, 746-756.

Liu, M. and Sadovy de Mitcheson, Y. (2008) Profile of a fishery collapse: Why mariculture failed to save the large yellow croaker. Fish and Fisheries 9, 219-242.

Lundgren, R., Staples, D.J., Funge-Smith, S.J. and Clausen, J. (2006) Status and Potential of Fisheries and Aquaculture in Asia and the Pacific 2006. FAO Regional Office for Asia and the Pacific. RAP PUBLICATION 2006/22., Bangkok, Thailand.

Mallory, T.G. (2016) Fisheries subsidies in China: Quantitative and qualitative assessment of policy coherence and effectiveness. Marine Policy 68, 74-82.

Miao, W. and Liao, M. (2007) Analysis of feeds and fertilizers for sustainable aquaculture development in China. FAO, 141-190.

MOA (2017a) China Fishery Statistical Yearbook 2017, 1st edn. China Agriculture Press, Beijing.

MOA (2017b) List of commercially important aquatic animals and plants under special state protection 
for resources. Available at: http://www.moa.gov.cn/sydw/stzz/zzzy/zzbh/201706/t20170608_5665914.htm [Accessed August 1, 2017].

MOA (2017c) Standard of catchable size of important fisheries species Part 1: Economic marine species. Available at: http://www.moa.gov.cn/govpublic/YYJ/201704/t20170401_5548770.htm [Accessed August 1, 2017].

Naylor, R.L., Goldburg, R.J., Primavera, J.H., et al. (2000) Effect of aquaculture on world fish supplies. Nature 405, 1017-1024.

Nguyen, T.T., Le, L.T., Tran, D.T., Cao, Q.L., Nguyen, H.T., Phan, D.N. and Tran, T.X. (2009) Project on development planning for aquaculture sector in the Mekong Delta up to 2015 and strategic planning up to 2020 (in Vietnamese). Ministry of Agriculrue \{\&\} Rural Development. Ho Chi Minh.

Parker, R.W.R. and Tyedmers, P.H. (2011) Uncertainty and natural variability in the ecological footprint of fisheries: A case study of reduction fisheries for meal and oil. Ecological Indicators, 6-13.

Pauly, D., Belhabib, D., Blomeyer, R., et al. (2014) China's distant-water fisheries in the 21st century. Fish and Fisheries 15, 474-488.

Pauly, D., Christensen, V., Dalsgaard, J., Froese, R. and Jr, F.T. (1998) Fishing Down Marine Food Webs. Science 279, 860-863.

Pikitch, E., Boersma, P.P.D., Boyd, I.L. IL, et al. (2012) Little Fish, Big impact: Managing a crucial link in ocean food webs. Washington, D.C., USA.

Pinsky, M.L., Jensen, O.P., Ricard, D. and Palumbi, S.R. (2011) Unexpected patterns of fisheries collapse in the world's oceans. Proceedings of the National Academy of Sciences 108, 83178322.

Qiu, Y. (2002) The situation of fishery resources in the northern South China Sea and the countermeasures for rational utilization (in Chinese). In: Survey China's exclusive economic zone and continental shelf. China Ocean Press, Beijing, pp 360-367.

Rindorf, A., Cardinale, M., Shephard, S., et al. (2017a) Fishing for MSY: using "pretty good yield" ranges without impairing recruitment. ICES Journal of Marine Scienc, fsw111.

Rindorf, A., Dichmont, C.M., Levin, P.S., et al. (2017b) Food for thought: pretty good multispecies yield. ICES Journal of Marine Scienc, fsw071.

Roberts, C.M., O’Leary, B.C., McCauley, D.J., et al. (2017) Marine reserves can mitigate and promote adaptation to climate change. Proceedings of the National Academy of Sciences 114, 6167-6175.

Sainsbury, K.J. (1984) Optimal mesh size for tropical multispecies trawl fisheries. ICES Journal of Marine Scienc 41, 129-139.

Shan, X., Sun, P., Jin, X., Li, X. and Dai, F. (2013) Long-Term Changes in Fish Assemblage Structure in the Yellow River Estuary Ecosystem, China. Marine and Coastal Fisheries 5, 65-78.

Shen, G. and Heino, M. (2014) An overview of marine fisheries management in China. Marine Policy 44, 265-272.

Shepherd, C.J. and Jackson, A.J. (2013) Global fishmeal and fish-oil supply: Inputs, outputs and marketsa. Journal of Fish Biology 83, 1046-1066.

Siriraksophon, S., Pangsorn, S. and Laong-manee, P. (2009) The Surimi Industry in Southest Asia: Trend and Demand for Raw Materials. Fish for the People People 7, 2-8.

Smith, A.D.M., Brown, C.J., Bulman, C.M., et al. (2011) Impacts of Fishing Low-Trophic Level 
Species on Marine Ecosystems. Science 1147, 1147-1150.

Smith, J. (1991) The Atlantic and Gulf Menhaden Purse Seine Fisheries: Origins, Harvesting

Technologies, Biostatistical Monitoring, Recent Trends in Fisheries Statistics, and Forecasting. Marine Fisheries Review 53, 28-41.

Sun, Z. (2014) The General Theory of fishing gears in the Yellow sea and the Bohai sea. China Ocean Press, Beijing.

Szuwalski, C.S., Burgess, M.G., Costello, C. and Gaines, S.D. (2017) High fishery catches through trophic cascades in China. Proceedings of the National Academy of Sciences 114, 717-721.

Tacon, A.G.J., Metian, M., Turchini, G.M. and De Silva, S.S. (2010) Responsible Aquaculture and Trophic Level Implications to Global Fish Supply. Reviews in Fisheries Science 18, 94-105.

Tsikliras, A.C. and Stergiou, K.I. (2014) Size at maturity of Mediterranean marine fishes. Reviews in Fish Biology and Fisheries 24, 219-268.

Tveteras, S., Paredes, C.E. and Peña-Torres, J. (2011) Individual Vessel Quotas in Peru: Stopping the Race for Anchovies. Marine Resource Economics 26, 225-232.

Wang, C. (2017) Review of fishmeal market in 2016 and prospects for 2017 (in Chinese). Feed China, 18-21.

Wang, L. and Yu, G. (2012) Marine fishing gears and fishing method and management in East China Sea. Zhejiang Science and Technology Publishing House, Hanzhou.

Watson, R., Alder, J. and Pauly, D. (2006) Fisheries for forage fish, 1950 to the present. In: On the multiple uses forage fish: from ecosystems to markets, Vol. 14. (eds J. Alder and D. Pauly). University of British Columbia, Vancouver, pp 1-19.

Yu, X. (2003) Implementation of minimum mesh size standards, Protection and rational use of fishery resources (in Chinese). China Fisheries, 74-77.

Zeller, D., Cashion, T., Palomares, M. and Pauly, D. (2018) Global marine fisheries discards: A synthesis of reconstructed data. Fish and Fisheries 19, 30-39.

Zhou, D. (2007) Quality safety for aquaculture products of China and its management. In: Global trade conference on aquaculture: 29-31 May 2007, Qingdao, China:[proceedings], Vol. 9. Food \{\&\} Agriculture Org., p 213.

Zhu, L. and Huang, S. (2014) The impact of fishery fuel subsidy policy on fishery resources and policy suggestions (in Chinese). Journal of Shanghai Ocean University 23, 618-622. 
Table 1. Characteristics of three fisheries catch categories.

\begin{tabular}{llll}
\hline Category & Food species & Forage species & Mixed species \\
\hline Targeted & Yes & Yes & No \\
Utilization $\dagger$ & Human food & Mostly feed & Mostly feed \\
Production scale & Medium to large & Small to large & Small to large \\
Commercially importance & High & Medium & Low \\
Planktivorous & Yes/No & Mostly Yes & Mostly No \\
Pelagic/Demersal & Demersal/Pelagic & Mostly pelagic & Mostly demersal \\
Market value & Medium to high & Low to medium & Low \\
Primary fishing gear & All & Midwater trawl & Bottom trawl \\
Example species & Groupers, & Anchovies, & Pinkgray goby \\
& yellow croaker & sardines & (Amblychaeturichthys \\
& (Larimichthys & & hexanema) \\
\hline
\end{tabular}

$\uparrow$ Marketed and used as such, and dependent on size of fish, quality of handling, volume available, time of year and location. 
Table 2. Proportions of feed grade fish in catches (by weight) from different fishing gears $(\mathrm{n}=886$ interviews $)$

\begin{tabular}{ll}
\hline Vessel type & Proportion of feed grade fish $(\%)$ \\
\hline Midwater trawler & $71.51 \pm 31.20(\mathrm{n}=76)^{\mathrm{a}}$ \\
Bottom trawler & $43.59 \pm 21.25(\mathrm{n}=336)^{\mathrm{b}}$ \\
Unspecified trawler $\dagger$ & $49.57 \pm 29.01(\mathrm{n}=126)^{\mathrm{b}}$ \\
Stow nets & $40.94 \pm 26.31(\mathrm{n}=151)^{\mathrm{b}}$ \\
Gillnets and entangling nets & $27.54 \pm 25.26(\mathrm{n}=55)^{\mathrm{cd}}$ \\
Surrounding nets and seine nets & $17.18 \pm 19.21(\mathrm{n}=87)^{\mathrm{d}}$ \\
Other $\ddagger$ & $7.63 \pm 6.37(\mathrm{n}=19)^{\mathrm{d}}$ \\
Transport ship & $43.50 \pm 29.56(\mathrm{n}=36)^{\mathrm{bc}}$ \\
\hline
\end{tabular}

Note: $\uparrow$ Unspecified trawler include both midwater trawler and bottom trawler, but not specified by the interviewees; $\$$ 'Other' category includes hooks and lines, pots, rakes and other miscellaneous gears. Independent-samples Kruskal-Wallis test was used for significance test using SPSS 22 statistic software (IBM 2013). Means superscripted by different letters indicate significant differences $(\mathrm{p}<0.05)$. 
Table 3. Proportions of feed grade fish in catches (by weight) from trawlers in eight provinces $(\mathrm{n}=538$ interviews)

\begin{tabular}{llll}
\hline Province & Bottom trawler $(\%)$ & Midwater trawler $(\%)$ & Unspecified trawler $(\%){ }^{\dagger}$ \\
\hline Liaoning & $36 \pm 35(\mathrm{n}=15)^{\mathrm{b}}$ & $94 \pm 8(\mathrm{n}=21)^{\mathrm{a}}$ & $23 \pm 40(\mathrm{n}=3)^{\mathrm{abc}}$ \\
Shandong & $35 \pm 26(\mathrm{n}=41)^{\mathrm{b}}$ & $85 \pm 13(\mathrm{n}=27)^{\mathrm{ab}}$ & $67 \pm 23(\mathrm{n}=15)^{\mathrm{a}}$ \\
Jiangsu & $33 \pm 29(\mathrm{n}=15)^{\mathrm{b}}$ & & $33 \pm 33(\mathrm{n}=9)^{\mathrm{abc}}$ \\
Zhejiang & $56 \pm 13(\mathrm{n}=51)^{\mathrm{a}}$ & $57 \pm 16(\mathrm{n}=5)^{\mathrm{bc}}$ & $35 \pm 32(\mathrm{n}=24)^{\mathrm{bc}}$ \\
Fujian & $40 \pm 18(\mathrm{n}=63)^{\mathrm{b}}$ & $26 \pm 34(\mathrm{n}=14)^{\mathrm{c}}$ & $9 \pm 12(\mathrm{n}=10)^{\mathrm{c}}$ \\
Guangdong & $31 \pm 13(\mathrm{n}=73)^{\mathrm{b}}$ & & $0 \pm 0(\mathrm{n}=3)^{\mathrm{bc}}$ \\
Guangxi & $58 \pm 11(\mathrm{n}=63)^{\mathrm{a}}$ & $51 \pm 0(\mathrm{n}=3)^{\mathrm{bc}}$ & $60 \pm 9(\mathrm{n}=11)^{\mathrm{ab}}$ \\
Hainan & $62 \pm 11(\mathrm{n}=15)^{\mathrm{a}}$ & $62 \pm 27(\mathrm{n}=6)^{\mathrm{bc}}$ & $65 \pm 14(\mathrm{n}=51)^{\mathrm{a}}$ \\
\hline
\end{tabular}

Note: $\uparrow$ Unspecified trawler include both midwater trawler and bottom trawler but not specified by the interviewees. Independent-samples Kruskal-Wallis test was used for significance test using SPSS 22 statistic software (IBM 2013). Means superscripted by different letters indicate significant differences $(\mathrm{p}<0.05)$. 
Table 4. Weighting factors and weighted proportion of feed grade fish in different fishing gears

\begin{tabular}{|c|c|c|c|c|c|}
\hline $\begin{array}{l}\text { Fishing } \\
\text { gear }\end{array}$ & Province & $\begin{array}{l}\text { Proportion of feed } \\
\text { grade fish } \\
\text { collected from } \\
\text { interview }(\mathrm{Pp}, \%)\end{array}$ & $\begin{array}{l}\text { Marine catch } \\
\text { in China's EEZ } \\
\text { in } 2016(\mathbf{P d} \text {, } \\
\mathrm{mt}) \dagger\end{array}$ & $\begin{array}{l}\text { Weighting } \\
\text { factors } \\
(\mathbf{W t}) \ddagger\end{array}$ & $\begin{array}{l}\text { Weighted proportion } \\
\text { of feed grade fish of } \\
\text { each fishing gear } \\
\text { category (WPp, \%)§ }\end{array}$ \\
\hline \multirow[t]{8}{*}{ Trawls } & Liaoning & 66.01 & 397,894 & 0.065075 & 48.70 \\
\hline & Shandong & 56.91 & $1,398,197$ & 0.228673 & \\
\hline & Jiangsu & 32.85 & 78,717 & 0.012874 & \\
\hline & Zhejiang & 49.62 & $2,103,225$ & 0.343980 & \\
\hline & Fujian & 33.80 & 778,343 & 0.127297 & \\
\hline & Guangdong & 29.70 & 749,572 & 0.122592 & \\
\hline & Guangxi & 58.20 & 425,929 & 0.069660 & \\
\hline & Hainan & 63.76 & 182,511 & 0.029849 & \\
\hline \multirow{7}{*}{$\begin{array}{l}\text { Surrounding } \\
\text { nets and } \\
\text { seine nets }\end{array}$} & Shandong & 60.01 & 36,735 & 0.033672 & 20.34 \\
\hline & Jiangsu & 55.56 & 5,724 & 0.005247 & \\
\hline & Zhejiang & 15.00 & 220,102 & 0.201749 & \\
\hline & Fujian & 1.51 & 311,547 & 0.285569 & \\
\hline & Guangdong & 37.50 & 143,089 & 0.131158 & \\
\hline & Guangxi & 25.18 & 62,174 & 0.056990 & \\
\hline & Hainan & 28.77 & 311,597 & 0.285615 & \\
\hline \multirow[t]{7}{*}{ Gillnet } & Liaoning & 8.33 & 491,656 & 0.220880 & 20.20 \\
\hline & Shandong & 39.24 & 416,024 & 0.186902 & \\
\hline & Jiangsu & 35.26 & 163,291 & 0.073360 & \\
\hline & Zhejiang & 27.88 & 319,057 & 0.143339 & \\
\hline & Fujian & 2.00 & 318,118 & 0.142917 & \\
\hline & Guangdong & 3.89 & 433,718 & 0.194851 & \\
\hline & Guangxi & 90.00 & 84,030 & 0.037751 & \\
\hline \multirow[t]{6}{*}{ Stow nets } & Liaoning & 21.92 & 95,891 & 0.065429 & 47.53 \\
\hline & Shandong & 51.69 & 190,367 & 0.129892 & \\
\hline & Jiangsu & 31.00 & 211,978 & 0.144638 & \\
\hline & Zhejiang & 47.18 & 613,130 & 0.418355 & \\
\hline & Fujian & 62.82 & 346,156 & 0.236191 & \\
\hline & Guangdong & 58.64 & 8,052 & 0.005494 & \\
\hline Others II & All & 0.00 & $1,360,431$ & - & 0 \\
\hline
\end{tabular}

Note: $\uparrow$ : Data source: (MOA 2017a); + : Weighting factors $\left(\mathrm{Wt}_{\mathrm{i}}\right)$ are calculated separately for each fishing gear category and based on production in each province $\left(\mathrm{Pd}_{\mathrm{i}}\right)$, as $\mathrm{Wt}_{\mathrm{i}}=\mathrm{Pd}_{\mathrm{i}} /$ $\sum_{i=1}^{n} \mathrm{Pd}_{\mathrm{i}}$, for each fishing gear category $\sum_{i=1}^{n} \mathrm{Wt}_{\mathrm{i}}=1 ; \S$ : Weighted proportion of feed grade fish of each fishing gear category (WPp) are calculated separately for each fishing gear category and based on proportion of feed grade fish collected from interview $\left(\mathrm{Pp}_{\mathrm{i}}\right)$ and its weighting factors $\left(\mathrm{Wt}_{\mathrm{i}}\right)$, as $\mathrm{WPp}=\sum_{i=1}^{n} \mathrm{Pp}_{\mathrm{i}} \times \mathrm{Wt}_{\mathrm{i}}$; 9 : 'Others' category includes hooks and lines, pots, 
rakes and other miscellaneous gears. The proportion of feed grade fish from 'Others' category was set at $0 \%$ due to the limited sample size of it. 
Table 5. Weighted means of proportion and production volume of feed grade fish in total landings in China

\begin{tabular}{|c|c|c|c|c|c|}
\hline Fishing gear & $\begin{array}{l}\text { Weighted } \\
\text { proportion of } \\
\text { feed grade fish } \\
(\mathrm{WPp}, \%) \dagger\end{array}$ & $\begin{array}{l}\text { Marine catch of } \\
\text { each fishing gear } \\
\text { category in } \\
\text { China's EEZ in } \\
2016 \text { (GPd, } \\
\text { mmt) } \ddagger\end{array}$ & $\begin{array}{l}\text { Overall } \\
\text { weighting } \\
\text { factors } \\
(O W t) \S\end{array}$ & $\begin{array}{l}\text { Overall } \\
\text { weighted } \\
\text { proportion of } \\
\text { feed grade fish } \\
(\text { OWPp, \%)ף }\end{array}$ & $\begin{array}{l}\text { Feed grade } \\
\text { fish } \\
\text { production } \\
\text { (FFPd, } \\
\text { mmt)\# }\end{array}$ \\
\hline Trawls & 48.70 & 6.23 & 0.469 & 34.69 & 3.03 \\
\hline $\begin{array}{l}\text { Surrounding nets } \\
\text { and seine nets }\end{array}$ & 20.34 & 1.10 & 0.083 & & 0.22 \\
\hline $\begin{array}{l}\text { Gillnets and } \\
\text { entangling nets }\end{array}$ & 20.20 & 3.04 & 0.229 & & 0.61 \\
\hline Stow nets & 47.53 & 1.55 & 0.117 & & 0.74 \\
\hline Others $\perp$ & 0.00 & 1.36 & 0.102 & & 0.00 \\
\hline \multicolumn{5}{|c|}{ Total catch in China's EEZ in 2016 (mmt) } & 13.28 \\
\hline \multicolumn{5}{|c|}{ Total feed grade fish production in China in $2016(\mathrm{mmt})$} & 4.61 \\
\hline
\end{tabular}

Note: $\uparrow$ : The weighted proportion of feed grade fish of each fishing gear category (WPp) please see Table 4. $\ddagger$ : Data source: (MOA 2017a); §: Overall weighting factors $\left(\mathrm{OWt}_{\mathrm{j}}\right)$ are calculated based on marine catch production of each fishing gear category in China's EEZ in $2016\left(\mathrm{GPd}_{\mathrm{j}}\right)$, as $\mathrm{OWt}_{\mathrm{j}}=\mathrm{GPd}_{\mathrm{j}} / \sum_{j=1}^{n} \mathrm{GPd}_{\mathrm{j}}$, and $\sum_{j=1}^{n} \mathrm{OWt}_{\mathrm{j}}=1 ; \mathrm{q}$ : Overall weighted proportion of feed grade fish (OWPp) are calculated based on weighted proportion of feed grade fish of each fishing gear category $\left(\mathrm{WPp}_{\mathrm{j}}\right)$ and overall weighting factors $\left(\mathrm{OWt}_{\mathrm{j}}\right)$, as $\mathrm{OWPp}=\sum_{j=1}^{n} \mathrm{WPp}_{\mathrm{j}} \times \mathrm{OWt}_{\mathrm{j}}$; \#: Feed grade fish production (FFPd) are calculated based on weighted proportion of feed grade fish of each fishing gear category $\left(\mathrm{WPp}_{\mathrm{j}}\right)$ and marine catch production of each fishing gear category in China's EEZ in $2016\left(\mathrm{GPd}_{\mathrm{j}}\right)$, as $\mathrm{FFPd}=\mathrm{WPp}_{\mathrm{j}} \times \mathrm{GPd}_{\mathrm{j}} ; \perp$ : 'Others' category includes hooks and lines, pots, rakes and other miscellaneous gears. The proportion of feed grade fish from 'Others' category was set at $0 \%$ due to the limited sample size of it. 


\section{Figure legends}

Figure 1. Proportions of feed grade fish in catches (by weight) from different fishing vessels classified by fishing gears and transport ship. 'Other' category includes hooks and lines, pots, rakes and other miscellaneous gears.

Figure 2. Proportions of feed grade fish in catches (by weight) from all types of trawlers in eight provinces (A) by proportion of feed grade fish and (B) by province $(n=538)$.

Figure 3. Proportions of feed grade fish in marine fisheries catches in different provinces.

Figure 4. Contribution of feed grade fish production (by weight proportion) in China by major producing province.

Figure 5. Feed grade fish consumption and other use, in different provinces. Using feed grade fish as direct feed or produce fishmeal was not specified in surveys conducted in Zhejiang province.

Figure 6. Estimated production and consumption of marine catch in China's EEZ. The proportions of forage and mixed species are based on data in Figure S2; the use of feed grade fish in Zhejiang was set at national average (Figure 5); the unit for all numbers is mmt.

Figure 7. Taxonomic coverage of feed grade fish samples. (A) Class (B) Order (C) Family

Figure 8. Number and the proportion of juveniles and adults in the samples in three categories (Food fish, Forage fish, Mixed fish). Unidentified individuals are those 
individuals identified to species level, but no available measurable body length.

Figure 9. Production of top 10 World's leading marine (domestic + distant) fisheries countries and production of feed grade fish in China's marine catch in 2016. Data source: (FAO 2017); Aquatic plants excluded. 